\title{
Expression and prognostic significance of Fanconi anemia group $D 2$ protein and breast cancer type 1 susceptibility protein in familial and sporadic breast cancer
}

\author{
LIANG FENG and FENG JIN \\ Department of Breast Surgery, The First Affiliated Hospital of China Medical University, \\ Shenyang, Liaoning 110001, P.R. China
}

Received May 14, 2018; Accepted January 21, 2019

DOI: $10.3892 / \mathrm{ol} .2019 .10046$

\begin{abstract}
Fanconi anemia group D2 protein (FANCD2) and breast cancer type 1 susceptibility protein (BRCA1), within the FA/BRCA pathway, are involved in the regulation of DNA damage repair, which is associated with breast cancer (BC) progression. The present study aimed to investigate BRCA1 and FANCD2 expression in breast cancer, and to highlight the association with patient clinical characteristics and prognoses. The BRCA1 and FANCD2 proteins were detected by immunohistochemistry in 335 tissue samples obtained from patients with BC, including 141 patients with familial BC (FBC), 147 patients with sporadic breast cancer (SBC) and 47 patients with benign breast tumors. Western blotting was used to detect the FANCD2 ubiquitination level in 56 frozen specimens that were randomly selected from the SBC group. Protein expression of BRCA1 in the FBC group was positively associated with tumor size, lymphatic invasion, Tumor-Node-Metastasis (TNM) stage, estrogen receptor (ER) status and FANCD2 expression. Protein expression of FANCD2 in the SBC group was positively associated with tumor size, TNM stage, ER status and Ki-67 index. Survival analyses revealed that BRCA1 expression was associated with the decreased disease-free survival (DFS) rate of patients with FBC (versus no BRCA1 expression) and that FANCD2 was associated with decreased DFS of patients with SBC (versus no FANCD expression). Univariable and multivariable analyses demonstrated that BRCA1 expression may be an independent prognostic factor in the FBC group. In the SBC group, FANCD2 high expression and low ubiquitination levels were considered as independent
\end{abstract}

Correspondence to: Dr Feng Jin, Department of Breast Surgery, The First Affiliated Hospital of China Medical University, 155 Nanjing North Street, Heping, Shenyang, Liaoning 110001, P.R. China

E-mail: jinfeng@cmu.edu.cn

Key words: breast cancer type 1 susceptibility protein, Fanconi anemia group D2 protein, familial breast cancer, sporadic breast cancer, prognosis prognostic factors. In conclusion, the present study suggested that BRCA1 and FANCD2 expression, and FANCD2 ubiquitination levels, may be considered of novel potential prognostic value in patients with $\mathrm{BC}$.

\section{Introduction}

Breast cancer (BC) is one of the most common malignancies in women, with $\sim 30 \%$ of all $\mathrm{BC}$ cases possessing genetic origins. Hereditary factors involve mutations of numerous genes, including the genes for breast cancer type 1 susceptibility protein/breast cancer type 2 susceptibility protein (BRCA1/2), cellular tumor antigen p53 (p53) and phosphatase and tensin homolog, and represent a familial aggregation, although a small proportion of hereditary BCs have no familial origin (1). The most frequent mutations in hereditary BCs involve the genes coding for BRCA1 and BRCA2 (1), which increase the risk of familial breast cancer (FBC) by $\sim 16 \%$ (2). Patients with FBC can pass these mutations to their children, who have a significantly increased risk of developing breast or ovarian cancer (3). However, the role of BRCA1/2 expression in sporadic breast cancer (SBC) remains unclear.

Fanconi anemia (FA) is a rare autosomal recessive disease that involves various types of cytopenias, congenital malformations and neoplastic diseases (4). In the FA pathway, which is mainly activated through the $\mathrm{S}$ phase of the cell cycle, DNA damage repair is regulated by interactions between a large number of proteins, including FA group A protein (FANCA), FANCB, FANCC, FANCD1 (also known as BRCA2), Fanconi anemia group D2 protein (FANCD2), FANCE, FANCF, FANCG, FANCI, BRCA1 interacting protein C-terminal helicase 1 (FANCJ), E3 ubiquitin-protein ligase FANCL (FANCL), FANCM, partner and localizer of BRCA2 (FANCN), DNA repair protein RAD51 homolog 3 (FANCO), SLX4 structure-specific endonuclease subunit (FANCP), DNA repair endonuclease XPF (FANCQ), DNA repair protein RAD51 homolog 1 (FANCR), FANCS (also known as BRCA1) and Ubiquitin-conjugating enzyme E2 T (FANCT) (5). When exogenous DNA damage induces replication blockage, the aborted replication fork activates nuclear FANCA, FANCB, FANCC, FANCE, FANCF, FANCG, FANCL and FANCM to form the upstream E3 ubiquitin ligase complex through 
phosphorylation modification. This complex is crucial for the downstream mono-ubiquitination of FANCD2 at Lys561, which represents the central step in FA pathway activation $(6,7)$. The FANCD2 gene encodes a 1,451-amino acid protein and comprises 44 exons that are located in 3p25.3, with a mutation probability of $3 \%(8,9)$. Ubiquitinated FANCD2 is considered as the long-form of FANCD2 (FANCD2-L; $162 \mathrm{kDa})$ compared with its non-ubiquitinated version FANCD2-S, which is $155 \mathrm{kDa}$. FANCD2-S conversion into FANCD2-L can be activated by DNA cross-linking agents, ultraviolet radiation and ionizing radiation in a time- and dose-dependent manner (10). The final step of ubiquitination involves the aggregation of ubiquitinated FANCD2 to DNA double-strand breaks, where it interacts with BRCA1/FANCS, BRCA2/FANCD1, FANCN, FANCJ, FANCP and other nuclear proteins to repair intra-DNA cross-link damage and maintain replication fork stability (9-13). FANCD2 therefore serves a central role in the FA pathway, and its ubiquitination is a crucial process in DNA damage repair.

BRCA1 is present in and co-colocalizes with the downstream FA pathway proteins (14). Domchek et al (15) reported that BRCA1 serves a central role in the FA pathway and that the BRCA1 gene may be involved in FA development. In this context, these findings suggest that BRCA1 mutation can increase the risk of $\mathrm{FBC}$, although its role in $\mathrm{SBC}$ remains unclear. Further studies are therefore required to determine the associations and prognostic value of BRCA1 and FANCD2 in FBC and SBC. The present study used immunohistochemistry and western blotting to detect BRCA1 and FANCD2 expression in FBC and SBC tissues samples, and aimed to evaluate their association with the clinical characteristics and prognosis of the patients.

\section{Materials and methods}

Patient selection and data collection. The present study was approved by the Ethics Committee of The First Affiliated Hospital of China Medical University (Shenyang, Liaoning, China). All enrolled patients provide written informed consent prior to the study.

Specimens from 335 patients with BC who underwent breast surgery between January 2004 and January 2009 at The First Affiliated Hospital of China Medical University were randomly selected. All patients had undergone modified radical mastectomy with no trace of distant metastasis at the diagnosis and received no neoadjuvant therapy prior to the study. The 335 BC cases comprised 141 FBC and 147 SBC cases, and 47 control cases of benign breast tumors. The FBC group included patients who had a first-degree relative with a history of $\mathrm{BC}$, whereas the SBC group included patients with no familial history of $\mathrm{BC}$. Clinical characteristics were retrospectively collected and included age, pathological type, histological grade, tumor size, lymph node infiltration, Tumor-Node-Metastasis (TNM) stage (16), estrogen receptor (ER), progesterone receptor (PR) and human epidermal growth factor receptor 2 (HER2) status, and Ki-67 index. All patients were followed up clinically until January 2016, and the disease-free survival (DFS) time was calculated from the time of surgery to the first occurrence of relapse, progression or mortality from any cause, or the last follow-up.
Immunohistochemistry. A standardindirectimmunoperoxidase protocol was used for the immunohistochemical analysis (17). Briefly, at room temperature, the paraffin-embedded tumor tissue sample were placed in $4 \%$ paraformaldehyde for $3 \mathrm{~h}$ and then $4-\mu \mathrm{m}$ thick sections were deparaffinized, rehydrated and blocked using 3\% hydrogen peroxide for $15 \mathrm{~min}$. Samples were then incubated at $120^{\circ} \mathrm{C}$ for $1 \mathrm{~min}$ to expose antigens, and allowed to cool to room temperature. Tissues were blocked with $1 \%$ bovine serum albumin (Reagent $\mathrm{A}$, KIT-9710 UltraSensitive ${ }^{\mathrm{TM}}$ SP (Mouse/Rabbit) IHC Kit, MXB Biotechnology) at room temperature to avoid non-specific binding, and labeled with the mouse anti-human primary antibodies against BRCA1 (cat. no. sc-56030; 1:200) and FANCD2 (cat. no. sc-20022; 1:150) (both Santa Cruz Biotechnology, Inc., Dallas, TX, USA). Sections were incubated with primary antibodies overnight at $4^{\circ} \mathrm{C}$ in a humidified chamber. Sections were then further incubated with the UltraSensitive ${ }^{\mathrm{TM}} \mathrm{SP}$ (Mouse/Rabbit) IHC kit (KIT-9710; Fuzhou Maixin Biotech Co., Ltd., Fuzhou, China) at room temperature for $10 \mathrm{~min}$ and visualized by staining with 3,30-diaminobenzidine tetrahydrochloride (Fuzhou Maixin Biotech Co., Ltd) at room temperature for $10 \mathrm{~min}$. Sections were counterstained with hematoxylin at room temperature for $10 \mathrm{~min}$, dehydrated in 75, 85,95 and $100 \%$ absolute ethanol for $2 \mathrm{~min}$ and covered with coverslips. Positive controls were selected from previously diagnosed sections at the Department of Pathology, The First Affiliated Hospital of China Medical University. Sections that were not stained with primary antibodies represented negative controls. Two pathologists independently scored each section by analyzing 10 fields under an optical microscope (magnification, $x 200$ ) that contained $>200$ cells. Nuclear and cytoplasmic staining for BRCA1 was scored as either negative, or mildly, moderately or strongly positive for $<5,5-25,25-50$ or $>50 \%$ stained cells, respectively (18). FANCD2 nuclear staining was scored as either negative, or mildy, moderately or strongly positive for $<5,5-25,25-50$ or $>50 \%$ stained cells, respectively (19). Patients with samples that were mildy, moderately or strongly stained were assigned to the positive expression group.

Western blotting. Western blotting was used to detect FANCD2 ubiquitination level in 56 randomly selected frozen SBC specimens. Tumor tissues were frozen in liquid nitrogen and homogenized using a membrane and cytosol protein extraction kit (cat.no. P0033; Beyotime Institute of Biotechnology, Haimen, China) to extract proteins. Tissues were crushed and washed with PBS and lysed in $100 \mu 1$ lysis buffer (catalog no. 78833; Thermo Fisher Scientific, Inc.). Cell lysates were centrifuged at room temperature, at 13,500 x g for $5 \mathrm{~min}$. Protein concentration was determined by the BCA method (catalog no. P0012S; Beyotime Institute of Biotechnology). Equal amounts of proteins $(50 \mu \mathrm{g})$ were separated by SDS-polyacrylamide gel electrophoresis, and transferred onto a nitrocellulose membrane (Bio-Rad Laboratories, Inc., Hercules, CA, USA). Membranes were blocked with 5\% fat-free milk diluted with TBST $(10 \mathrm{mM}$ Tris-HCl, $\mathrm{Ph} 7.4,150 \mathrm{mM} \mathrm{NaCl}, 0.1 \%$ Tween-20) at room temperature for $1 \mathrm{~h}$ and incubated for $1 \mathrm{~h}$ with the rabbit anti-human primary antibodies against FANCD2 (cat. no. sc-28194; $1: 1,000$ ) and $\beta$-actin (cat. no. sc-47778; 1:3,000) (both Santa Cruz Biotechnology). Membranes were then incubated with a 
Table I. Demographic and clinical characteristics of patients with BC in the FBS ( $\mathrm{n}=141)$ and SBC (n=147) groups.

\begin{tabular}{|c|c|c|c|c|c|}
\hline \multirow[b]{2}{*}{ Patients characteristics } & \multicolumn{2}{|c|}{ FBC } & \multicolumn{2}{|c|}{ SBC } & \multirow[b]{2}{*}{ Total, $\mathrm{n}$} \\
\hline & Value & $\%$ & Value & $\%$ & \\
\hline \multicolumn{6}{|l|}{ Age in years } \\
\hline Median (range) & $52(31-76)$ & & $50(25-79)$ & & \\
\hline$<51, \mathrm{n}$ & 69 & 48.9 & 75 & 51.0 & 144 \\
\hline$\geq 51, \mathrm{n}$ & 72 & 51.1 & 72 & 49.0 & 144 \\
\hline \multicolumn{6}{|l|}{ Pathological type } \\
\hline In situ & 21 & 14.9 & 18 & 12.2 & 39 \\
\hline Invasive ductal carcinoma & 81 & 57.4 & 91 & 61.9 & 172 \\
\hline Invasive lobular carcinoma & 25 & 17.7 & 22 & 15.0 & 47 \\
\hline Others & 14 & 9.9 & 16 & 10.9 & 30 \\
\hline \multicolumn{6}{|l|}{ Histological grade } \\
\hline I & 43 & 30.5 & 31 & 21.1 & 74 \\
\hline II & 67 & 47.5 & 78 & 53.1 & 145 \\
\hline III & 31 & 22.0 & 38 & 25.9 & 69 \\
\hline \multicolumn{6}{|l|}{ Tumor size } \\
\hline $\mathrm{T} 1$ & 63 & 44.7 & 72 & 49.0 & 135 \\
\hline $\mathrm{T} 2$ & 61 & 43.3 & 63 & 42.9 & 124 \\
\hline T3 & 16 & 11.3 & 12 & 8.2 & 28 \\
\hline $\mathrm{T} 4$ & 1 & 0.7 & 0 & 0.0 & 1 \\
\hline \multicolumn{6}{|l|}{ Node involvement } \\
\hline Positive & 63 & 44.7 & 56 & 38.1 & 119 \\
\hline Negative & 78 & 55.3 & 91 & 61.9 & 169 \\
\hline \multicolumn{6}{|l|}{ TNM stage } \\
\hline I & 61 & 43.3 & 55 & 37.4 & 116 \\
\hline II & 51 & 36.2 & 56 & 38.1 & 107 \\
\hline III & 29 & 20.6 & 36 & 24.5 & 65 \\
\hline IV & 0 & 0.0 & 0 & 0.0 & 0 \\
\hline \multicolumn{6}{|l|}{ ER status } \\
\hline Positive & 82 & 58.2 & 80 & 54.4 & 162 \\
\hline Negative & 59 & 41.8 & 67 & 45.6 & 126 \\
\hline \multicolumn{6}{|l|}{ PR status } \\
\hline Positive & 67 & 47.5 & 78 & 53.1 & 145 \\
\hline Negative & 74 & 52.5 & 69 & 46.9 & 143 \\
\hline \multicolumn{6}{|l|}{ HER2 status } \\
\hline Positive & 56 & 39.7 & 57 & 38.8 & 113 \\
\hline Negative & 85 & 60.3 & 90 & 61.2 & 175 \\
\hline \multicolumn{6}{|l|}{ Ki-67 } \\
\hline$\geq 15 \%$ & 84 & 59.6 & 88 & 59.9 & 162 \\
\hline$<15 \%$ & 57 & 40.4 & 59 & 40.1 & 126 \\
\hline
\end{tabular}

BRCA1, breast cancer type 1 susceptibility protein; FANCD2, Fanconi anemia group D2 protein; ER, estrogen receptor; FBC, familial breast cancer; HER2, human epidermal growth factor receptor 2; PR, progesterone receptor; SBC, sporadic breast cancer; TNM, Tumor-Node-Metastasis.

horseradish peroxidase-conjugated goat anti-rabbit secondary antibody (1:5,000; cat. no. A0545; Sigma-Aldrich; Merck $\mathrm{KGaG})$ at room temperature for $1 \mathrm{~h}$. Membranes were washed three times for $5 \mathrm{~min}$, and visualized using a Pierce enhanced chemiluminescence substrate (Thermo Fisher Scientific, Inc., Waltham, MA, USA). Gel-pro software (version 6.0; Media
Cybernetics, Inc., Rockville, MD, USA) was used to analyze the net absorbance values of protein bands and internal reference bands. FA proteins were visualized as two bands, of which the upper (L) and lower (S) bands represented the ubiquitinated and un-ubiquitinated FANCD2, respectively. The L/S ratio indicated the FANCD2 ubiquitination degree $(20,21)$. 

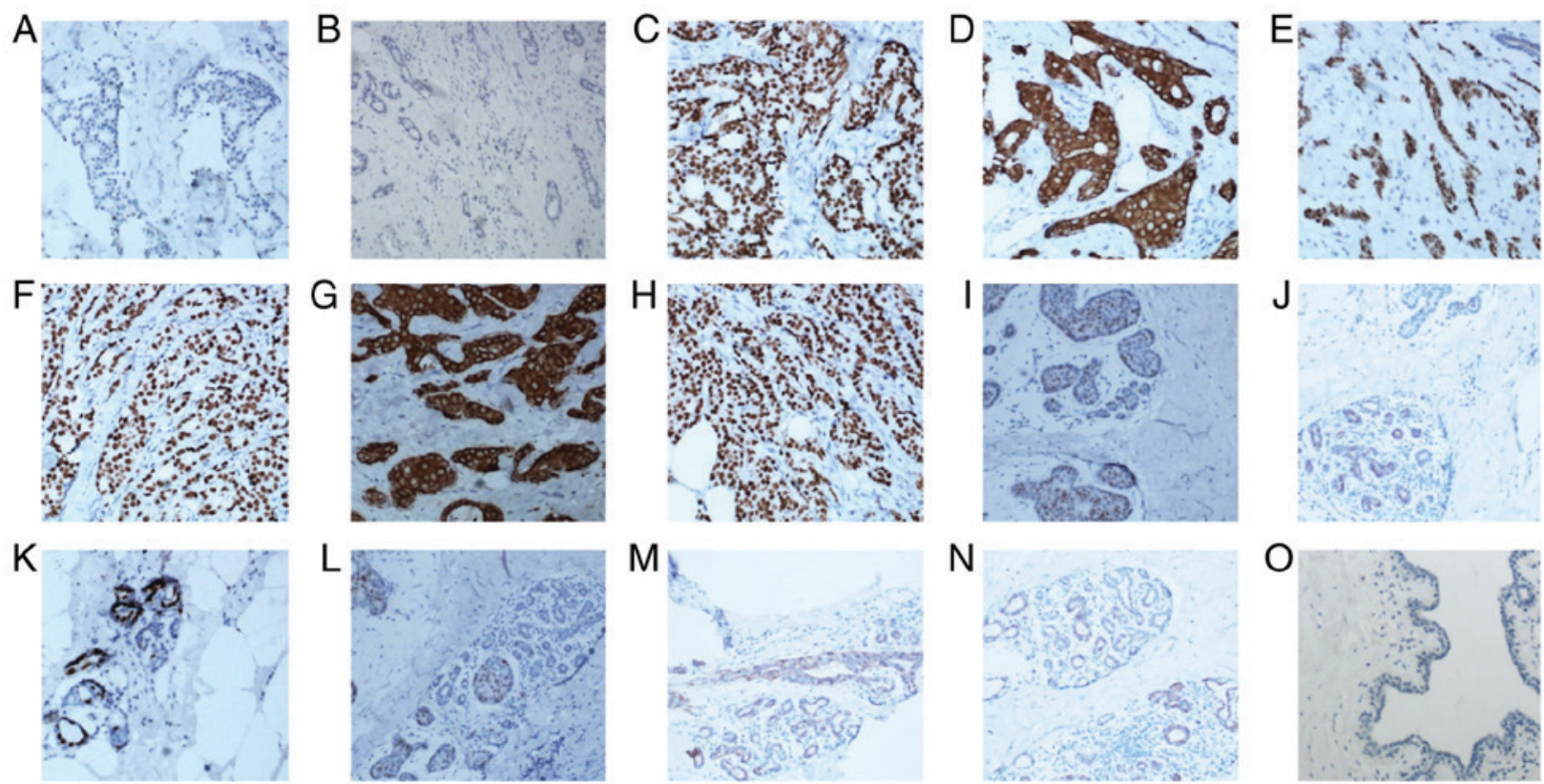

Figure 1. Representative images of BRCA1 and FANCD2 staining in benign and malignant tumor tissues of patients with BC at $\mathrm{x} 200$ magnification. (A) Negative control of BRCA1 in BC tissues. (B) Negative control of FANCD2 in BC tissue. Positive control of BRCA1 in (C) the nuclei and (D) cytoplasm of BC tissue. (E) Positive control of FANCD2 in the nuclei of BC tissues. (F) Positive expression of BRCA1 in the nuclei, (G) BRCA1 in the cytoplasm and (H) FANCD2 in the nuclei of BC tissues. Positive expression of (I) BRCA1 in the nuclei, (J) BRCA1 in the cytoplasm and (K) FANCD2 in the nuclei of the tissues adjacent to the carcinoma. Positive expression of (L) BRCA1 in the nuclei, (M) BRCA1 in the cytoplasm and (N) FANCD2 in the nuclei of benign tissues. (O) Negative expression of FANCD2 in benign tissue. BC, breast cancer; BRCA1, breast cancer type 1 susceptibility protein; FANCD2 Fanconi anemia group D2 protein.

Statistical analysis. All statistical analysis was performed using SPSS 24.0 (IBM Corp., Armonk, NY, USA). P<0.05 was considered to indicate a statistically significant difference. Patient clinical characteristics were compared using the $\chi^{2}$ test. Survival analyses were assessed using the Kaplan-Meier (KM) method and the two-tailed log-rank test. Univariable and multivariable analyses were performed using a Cox proportional hazard model to evaluate the effects of BRCA1 and FANCD2 expression on DFS. Results were reported as hazard ratios (HRs) and 95\% confidence intervals (CI).

Expression of BRCA1 and FANCD2 based on The Cancer Genome Atlas (TCGA) dataset. Further analyses of BRCA1 and FANCD2 gene expression in BC tissues were conducted based on The Cancer Genome Atlas (TCGA) dataset (https://cancergenome.nih.gov/) (22). In addition, the Gene Expression Profiling Interactive Analysis (GEPIA) dataset (http://gepia.cancer-pku.cn/) was used to compare BRCA1 and FANCD2 gene expression between BC tissues and their adjacent non-cancerous tissues (23). GEPIA data were analyzed using an unpaired Student's t-test. To verify the associations between BRCA1 and FANCD2 gene expression and clinical characteristics, data obtained from 1,080 patients with $\mathrm{BC}$ in the TCGA dataset were analyzed using the $\chi^{2}$ test.

\section{Results}

Patient clinical characteristics. The 47 women included in the benign tumor group presented with various types of tumors, including fibroadenoma, cystic hyperplasia, intraductal papilloma and sclerosing adenosis (15, 24, 7 and 1 cases, respectively), and had a median age at diagnosis of 46 years (range, 18-71 years). The remaining 288 women with primary malignant breast cancer (Table I) were divided into the FBC $(n=141)$ and SBC $(n=147)$ groups. Patients in the FBC and SBC groups had a median age at diagnosis of 52 years (range, 31-76 years) and 50 years (range, 25-79 years), respectively. The malignant tumors included intraductal carcinoma, invasive ductal carcinoma, invasive lobular carcinoma and other rare types (39, 172, 47 and 30 cases, respectively). The histological types were predominantly of type I (FBC, 30.5\%; SBC, 21.1\%) and type II (FBC, 47.5\%; SBC, 53.1\%), and large proportions of the tumors were considered as stage $\mathrm{T} 1$ (46.9\%), T2 (43.1\%) or involving lymphatic invasion (41\%). According to the 2017 American Joint Committee on Cancer criteria (24), the majority of patients had stage I (FBC, 43.3\%; SBC, 37.4\%) or stage II (FBC, 36.2\%; SBC, 38.1\%) disease. The follow-up ended in January 2016, with a median follow-up time of 74.4 months (range, 4-155 months). The median DFS time was 91.8 months, with 1-, 3- and 5-year DFS rates of 97.9, 91.7 and $83.3 \%$, respectively. A total of $24(8.33 \%)$ local recurrences and $29(10.08 \%)$ distant metastases occurred within 5 years.

Immunohistochemical staining for BRCA1 and FANCD2. The typical staining for BRCA1 was nuclear and cytoplasmic in the benign and malignant tissues (Fig. 1). Negative and positive controls were selected from previously diagnosed sections at the Department of Pathology, The First Affiliated Hospital of China Medical University. Positive expression of BRCA1 was associated with a significantly higher 5-year DFS rate in the FBC group (99/141, 70.2\%) compared with the SBC group $(21 / 147,14.3 \%$; $\mathrm{P}<0.001)$. The typical staining for FANCD2 was predominantly nuclear in the benign and malignant tissues (Fig. 1D-H). Positive expression of FANCD2 was associated 


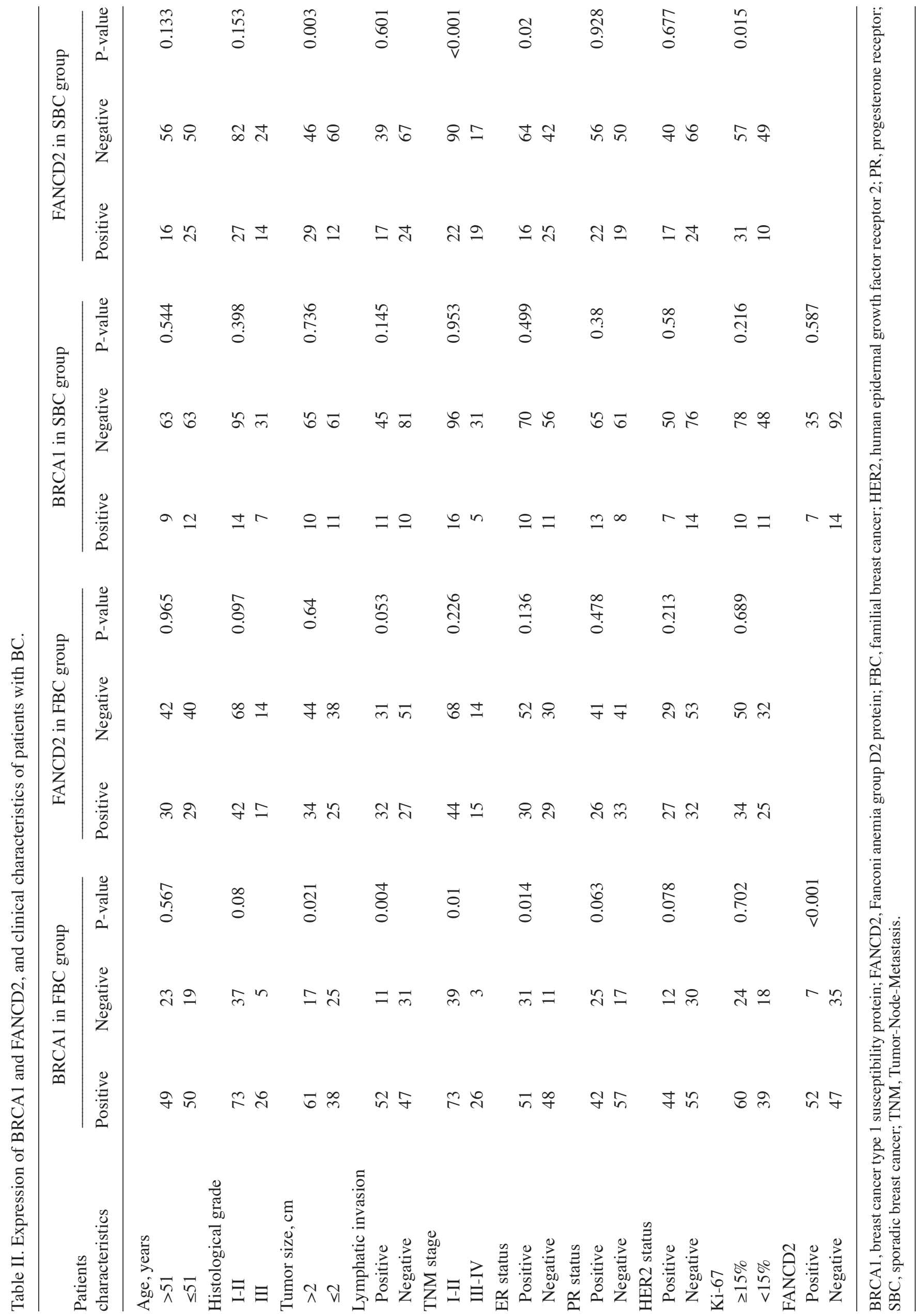



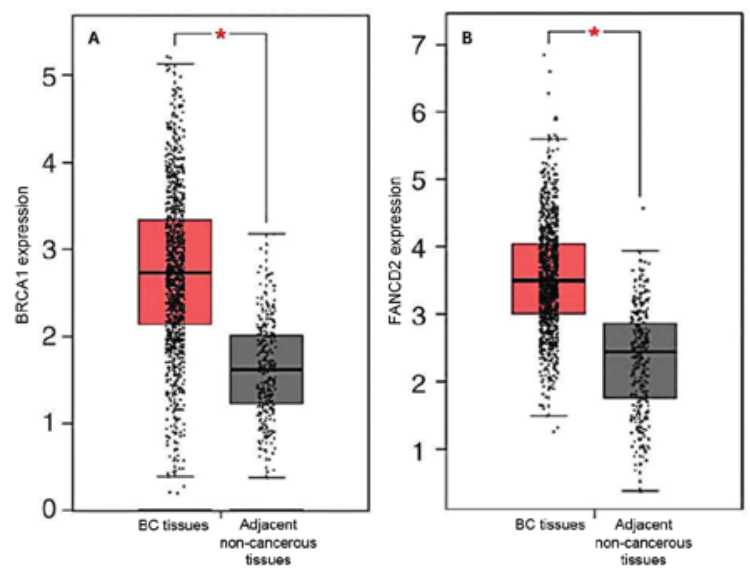

Figure 2. Comparisons of (A) BRCA1 and (B) FANCD2 expression levels between breast cancer tissues and non-cancerous adjacent tissues. The red bar represents the tumor tissues and the gray bar indicates the non-cancerous adjacent tissues. These figures were derived from the Gene Expression Profiling Interactive Analysis dataset. ${ }^{*} \mathrm{P}<0.05$. BRCA1, breast cancer type 1 susceptibility protein; FANCD2 Fanconi anemia group D2 protein.

with a significantly higher 5-year DFS rate in the FBC group (59/141, 41.8\%) compared with the SBC group (42/147, 28.6\%) $(\mathrm{P}=0.037)$. Table II presents the clinical characteristics of the patients and the expression levels of BRCA1 and FANCD2. Expression of BRCA1 in the FBC group was positively associated with tumor size $(\mathrm{P}=0.021)$, lymphatic invasion $(\mathrm{P}=0.004)$, TNM stage $(\mathrm{P}=0.01)$, ER status $(\mathrm{P}=0.014)$ and FANCD2 expression $(\mathrm{P}<0.001)$. These associations were not observed in the SBC group. However, FANCD2 expression in SBC group was positively associated with tumor size $(\mathrm{P}=0.003)$, TNM stage $(\mathrm{P}<0.001)$, ER status $(\mathrm{P}=0.02)$ and $\mathrm{Ki}-67$ index $(\mathrm{P}=0.015)$. The benign tissues were commonly positive for BRCA1 (29/47, 61.7\%) and FANCD2 (21/47, 44.7\%). There was no significant association between the expression of the two proteins $(\mathrm{P}=0.587)$. BRCA1 and FANCD2 expression was predominantly positive in the benign tissues compared with that in the SBC tissues (BRAC1, 61.7 vs. 14.3\%, $\mathrm{P}<0.001$; and FANCD2, 7 vs. $27.9 \%, \mathrm{P}=0.069$ ).

Further analysis of BRCA1 and FANCD2 expression in breast cancer based on TCGA data. Immunohistochemistry revealed that BRCA1 and FANCD2 were expressed in BC tissues and adjacent tissues. Analysis of the GEPIA dataset demonstrated that BRCA1 and FANCD2 gene expression in BC tissues was higher than that in adjacent tissues (Fig. 2). Furthermore, associations between FANCD2 and BRCA1 gene expression and patient clinical characteristics were assessed using TCGA dataset. The results revealed from TCGA dataset were slightly different from the results of the tissue samples analysis due to variations in the samples grouping (Table III). BRCA1 and FANCD2 gene expression in TCGA dataset was positively associated with tumor size (both $\mathrm{P}<0.001$ ) and ER expression (both $\mathrm{P}<0.001)$. In addition, BRCA1 and FANCD2 gene expression demonstrated a positive association. Furthermore, FANCD2 gene expression in TCGA dataset was positively associated with $P R$ stage $(\mathrm{P}<0.001)$, lymphatic invasion $(\mathrm{P}=0.017)$ and TNM stage $(\mathrm{P}=0.039)$. Results from TCGA dataset analysis were consistent with those from tissues samples analyses.
Prognostic value of BRCA1 and FANCD2 expression. The KM curves were compared according to BRCA1 and FANCD2 status and grouping. In the FBC group, BRCA1 expression was associated with a significantly decreased DFS rate when compared with the absence of BRCA1 expression $(\mathrm{P}=0.001$; Fig. 3A). This observation was associated with a lower 5-year DFS rate (77.8 vs. $95.2 \%)$ and a shorter median DFS time (81.4 vs. 108.8 months). However, in the FBC group, there was no significant difference in prognosis whether FANCD2 expression was positive or not $(\mathrm{P}=0.328$; Fig. 3B), although the group with positive FANCD2 expression had a lower 5-year DFS rate (78 vs. $86.6 \%$ ) and a shorter median DFS time (79.7 vs. 96.7 months). In the SBC group, BRCA1 expression was not associated with a significant difference in DFS rate $(\mathrm{P}=0.22$; Fig. 3C), although the group with positive BRCA1 expression had a slightly lower 5-year DFS rate (76.2 vs. 84.9\%) and a shorter median DFS time (92 vs. 94.3 months). In the SBC group, FANCD2 expression was associated with significantly decreased DFS rate $(\mathrm{P}<0.001$; Fig. 3D), with a lower 5-year DFS rate (63.4 vs. $91.5 \%)$ and a shorter median DFS time $(69.7$ vs. 103.3 months). These results suggested that BRCA1 and FANCD2 expression may be considered of prognostic value in patients with $\mathrm{FBC}$ and $\mathrm{SBC}$, respectively.

Univariable and multivariable analyses of DFS rate in patients with $B C$. Univariable analyses revealed that DFS rate in patients with FBC was significantly associated with TNM stage $(\mathrm{P}=0.001)$ and BRCA1 expression $(\mathrm{P}=0.001)$. DFS rate in patients with SBC was significantly associated with tumor size $(\mathrm{P}=0.001)$, lymphatic invasion $(\mathrm{P}=0.004)$, TNM stage $(\mathrm{P}<0.001), \mathrm{Ki}-67$ index $(\mathrm{P}=0.025)$ and FANCD2 expression $(\mathrm{P}<0.001)$. Multivariable Cox proportional hazards model demonstrated that DFS rate in patients with FBC was independently predicted by TNM stage (III-IV vs. I-II; HR, 2.042; 95\% CI, 1.150-3.624; $\mathrm{P}=0.015$ ) and BRCA1 expression (positive vs. negative; HR, 2.168; 95\% CI, 1.142-4.113; $\mathrm{P}=0.018$ ). In the SBC group, DFS rate was independently predicted by TNM stage (III-IV vs. I-II; HR, 4.361; 95\% CI, 2.465-7.716; $\mathrm{P}<0.001$ ) and FANCD2 expression (positive vs. negative; HR, 1.192; 95\% CI, 1.041-3.512; $\mathrm{P}=0.037$ ) (Table IV).

FANCD2 ubiquitination is an independent prognostic factor for patients with SBC. FANCD2 ubiquitination reflects functional activation of the FA pathway $(7,9)$. Results from the present study demonstrated that FANCD2 expression was an independent prognostic factor for SBC. Western blotting of 56 randomly selected SBC tissues was performed to examine whether FANCD2 ubiquitination was associated with prognosis. Expression of FANCD2-L and FANCD2-S (Figs. 4 and S1) was used to calculate the L/S ratio to quantify FANCD2 ubiquitination. L/S ratios ranged from 0.13 to 1.36 (median, 0.645; Fig. 5). The 56 cases were subsequently divided according to their $\mathrm{L} / \mathrm{S}$ value into the ubiquitination ${ }^{\text {High }}$ $\left(\mathrm{Ub}^{\text {High }}, \geq 0.645\right.$ ) group and the ubiquitination ${ }^{\text {Low }}\left(\mathrm{Ub}^{\text {Low }}\right.$, $<0.645)$ group. Representative western blotting is presented in Figs. 4 and S1. Patients in the $\mathrm{Ub}^{\mathrm{High}}$ group had significantly higher DFS than patients in the $\mathrm{Ub}^{\text {Low }}$ group ( $\mathrm{P}=0.036$; Fig. 6). In the FBC group, patients with $\mathrm{Ub}^{\text {High }}$ had a significantly higher 5-year DFS rate (85.7 vs. $71.4 \%$ ) and a significantly higher median DFS time (101.2 vs. 73.4 months) compared 
Table III. Expression of BRCA1 and FANCD2, and clinical characteristics of patients with breast cancer obtained from The Cancer Genome Atlas dataset.

\begin{tabular}{|c|c|c|c|c|c|c|}
\hline \multirow[b]{2}{*}{ Patients characteristics } & \multicolumn{3}{|c|}{ BRCA1 } & \multicolumn{3}{|c|}{ FANCD2 } \\
\hline & High, $n$ & Low, $\mathrm{n}$ & P-value & High, $n$ & Low, $\mathrm{n}$ & P-value \\
\hline \multicolumn{7}{|l|}{ Age, years $(n=1,078)$} \\
\hline$>58$ & 288 & 275 & 0.428 & 272 & 291 & 0.241 \\
\hline$\leq 58$ & 251 & 264 & & 267 & 248 & \\
\hline \multicolumn{7}{|l|}{ Tumor size, $\mathrm{cm}(\mathrm{n}=1,077)$} \\
\hline$>2$ & 389 & 409 & $<0.001$ & 492 & 306 & $<0.001$ \\
\hline$\leq 2$ & 98 & 181 & & 116 & 163 & \\
\hline \multicolumn{7}{|c|}{ Lymphatic invasion ( $\mathrm{n}=914)$} \\
\hline Positive & 234 & 229 & 0.32 & 213 & 250 & 0.017 \\
\hline Negative & 222 & 229 & & 243 & 208 & \\
\hline \multicolumn{7}{|l|}{ TNM stage $(\mathrm{n}=768)$} \\
\hline $\mathrm{I}-\mathrm{II}$ & 302 & 292 & 0.32 & 309 & 285 & 0.039 \\
\hline III-IV & 81 & 93 & & 76 & 100 & \\
\hline \multicolumn{7}{|l|}{$\mathrm{ER}(\mathrm{n}=1,024)$} \\
\hline Positive & 390 & 400 & $<0.001$ & 346 & 445 & $<0.001$ \\
\hline Negative & 48 & 187 & & 167 & 68 & \\
\hline \multicolumn{7}{|l|}{$\mathrm{PR}(\mathrm{n}=1,024)$} \\
\hline Positive & 340 & 346 & 0.691 & 302 & 384 & $<0.001$ \\
\hline Negative & 173 & 167 & & 211 & 129 & \\
\hline \multicolumn{7}{|l|}{ HER2 $(n=611)$} \\
\hline Positive & 150 & 134 & 0.158 & 136 & 148 & 0.739 \\
\hline Negative & 154 & 173 & & 161 & 166 & \\
\hline \multicolumn{7}{|l|}{ FANCD2 $(n=1,080)$} \\
\hline Negative & 289 & 253 & 0.031 & & & \\
\hline Positive & 253 & 288 & & & & \\
\hline
\end{tabular}

BRCA1, breast cancer type 1 susceptibility protein; FANCD2, Fanconi anemia group D2 protein; ER, estrogen receptor; FBC, familial breast cancer; HER2, human epidermal growth factor receptor 2; PR, progesterone receptor; SBC, sporadic breast cancer; TNM, Tumor-Node-Metastasis .

with patients with $\mathrm{Ub}^{\text {Low }}$. Results from the univariable and multivariable analyses are presented in Table V. Univariable analysis revealed that the DFS rate in patients with SBC was significantly associated with ubiquitination level $(\mathrm{P}=0.042)$. Multivariable analyses revealed that, in addition to TNM stage $(\mathrm{P}=0.003)$ and FANCD2 expression $(\mathrm{P}=0.006)$, FANCD2 ubiquitination independently predicted DFS in the SBC group ( $\mathrm{Ub}^{\mathrm{High}}$ vs. Ub $\mathrm{Ub}^{\text {Low }}$ HR, 0.335; 95\% CI, 0.128-0.875; P=0.026) (Table V).

\section{Discussion}

$\mathrm{BC}$ is the most common malignant tumor in women in developed countries, and 10-30\% of cases involve a family history, which represents a strong risk factor for BC (25). Based on its etiology, BC can be divided into two groups, SBC and FBC, where $\mathrm{FBC}$ involves a direct family history of $\mathrm{BC}$. Compared with SBC, FBC affects younger women and is often associated with lymph node metastasis and negative hormone receptor expression, which leads to a poor prognosis (26).
Mutations of BRCA1/2 genes increase female susceptibility to BC and are closely associated with FBC. BRCA1 is involved in DNA damage repair and cell cycle regulation, and $\sim 45 \%$ of FBC cases comprise BRCA1 mutations. Conversely, SBC is less frequently associated with gene mutations or deletions, with BRCA1/2 mutations being relatively rare in SBC $(27,28)$. The present study used immunohistochemical analysis, which cannot detect deleterious BRCA1 mutations, however, aids in understanding tumor cell physiology and confirming BRCA1 protein involvement in breast tumor cells (29). Previous studies reported that BRCA1 is less likely to be expressed and mutated in SBC $(30,31)$. The present study highlighted a positive association between BRCA1 expression and tumor size in the FBC group, although this result was not in accordance with previous findings $(31,32)$. This difference may be due to the inclusion in the present study of patients with first-degree relatives who had breast cancer, and/or ethnicity differences. In addition, BRCA1 expression in the FBC group was associated with lymphatic invasion and TNM stage, which 

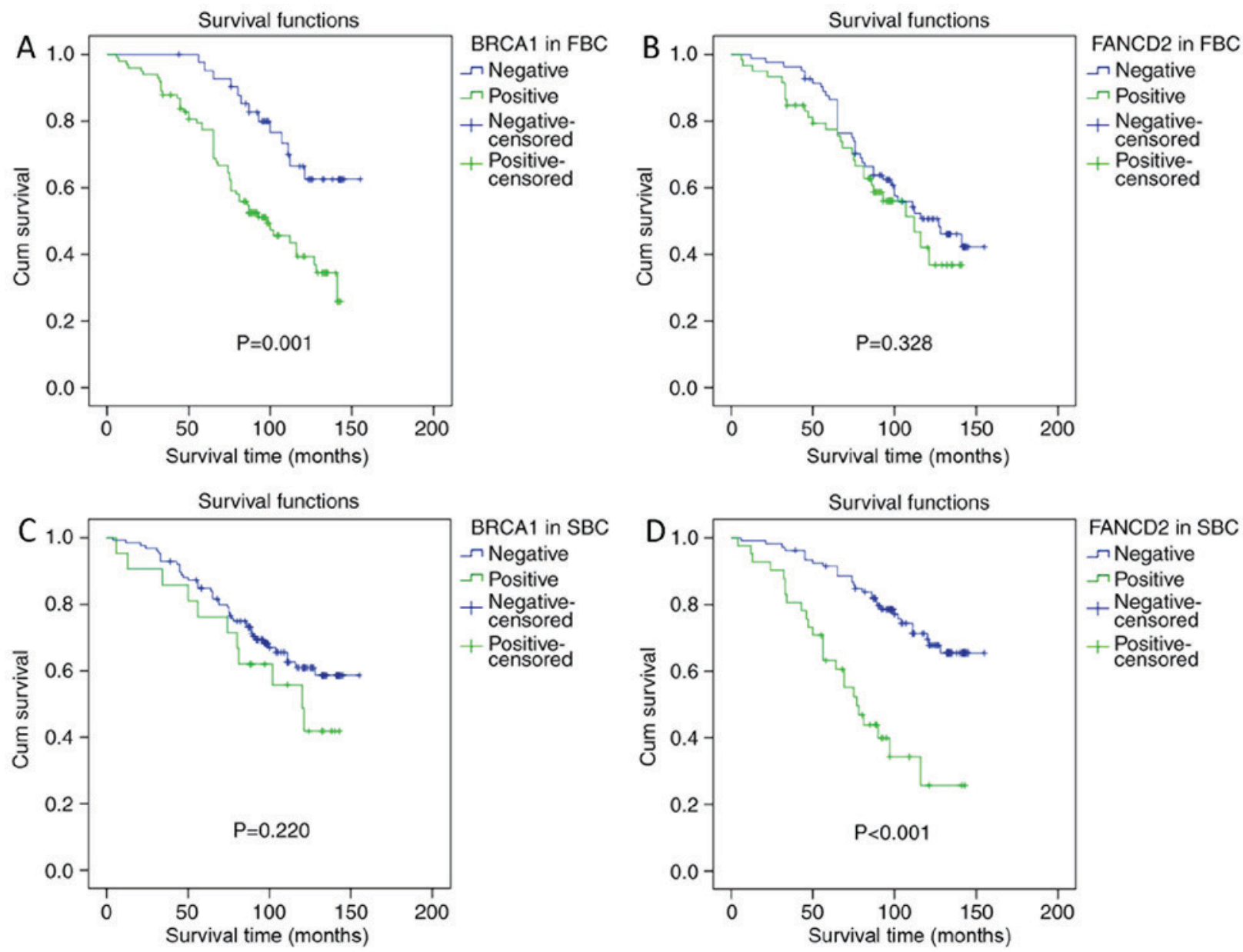

Figure 3. DFS of patients with breast cancer based on BRCA1 and FANCD2 expression. DFS of patients with FBC grouped by positive or negative expression of (A) BRCA1 and (B) FANCD2. DFS of patients with SBC were divided by positive or negative expression of (C) BRCA1 and (D) FANCD2. Probabilities of DFS were estimated using the Kaplan-Meier method and compared using the log-rank statistic. BRCA1, breast cancer type 1 susceptibility protein; FANCD2, Fanconi anemia group D2 protein; Cum, cumulative; DFS, disease-free survival; FBC, familial breast cancer; SBC, sporadic breast cancer.

was consistent with previous findings $(26,27)$. A negative association was observed between ER status and BRCA1 expression in the FBC group, as previously demonstrated by Tazzite et al (26). However, BRCA1 expression was not associated with these same factors in the SBC group. Previous studies have reported that BRCA1 expression is upregulated in $\mathrm{BC}$ tissues compared with that in benign breast tissues $(33,34)$, which was also demonstrated in the present study.

The present study demonstrated that larger tumor size, lymphatic invasion, higher TNM stage, negative ER expression and positive BRCA1 expression were associated with poor prognosis in patients with FBC. Scully and Livingston (35) reported that BRCA1 overexpression inhibits ER activation and that $\mathrm{FBC}$ cases are associated with negative ER expression. These findings suggest that BRCA1 may exert its tumor inhibition activity via ER. To test this hypothesis, univariable and multivariable analyses were performed in the present study, and results confirmed that BRCA1 expression was an independent prognostic factor for $\mathrm{FBC}$.

Exogenous and endogenous factors, including ionizing radiation and chemical exposure, can lead to various types of DNA damage, although a DNA repair system aids in maintaining the stability and integrity of the human genome (36). Cross-linking is a common type of DNA damage that requires a complex repair process that mainly involves the FA pathway. Ubiquitination of FANCD2 is recognized as an important activation step in the FA pathway for DNA damage repair. Lyakhovich and Surralles (37) reported that inhibition of FANCD2 expression increases tumor cells sensitivity to mitomycin and $\gamma$ rays, and that tumor cells with FANCD2 deletion have a significantly reduced ability to relapse. In sporadic ovarian cancer, Wysham et al (38) reported a high FANCD2 expression level in patients with early recurrence, and suggested that high FANCD2 expression is positively associated with early ovarian cancer risk. The present study revealed that FANCD2 expression was associated with tumor size, TNM stage and ER expression in the SBC group. These findings were in agreement with those from the study by van der Groep et al (39). Hölzel et al (40) similarly reported that the highest FANCD2 expression is observed in mature spermatocytes and fetal oocytes, which rapidly become proliferating germ cells. In addition, a high Ki-67 index typically reflects highly proliferative cells and rapid tumor progression (41). Furthermore, FANCD2 and $\mathrm{Ki}-67$ co-localize in BC cells, which suggests that FANCD2 serves a role in the DNA repair of proliferating cells. Results 


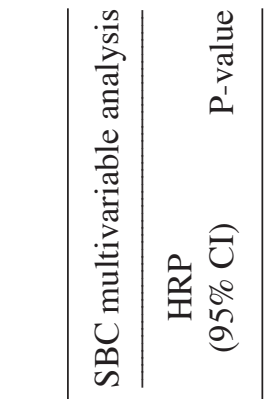

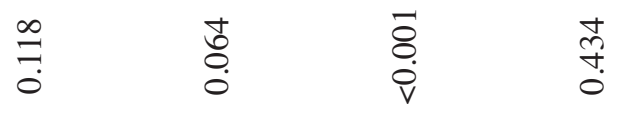

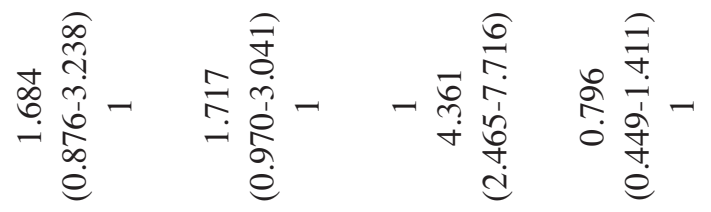

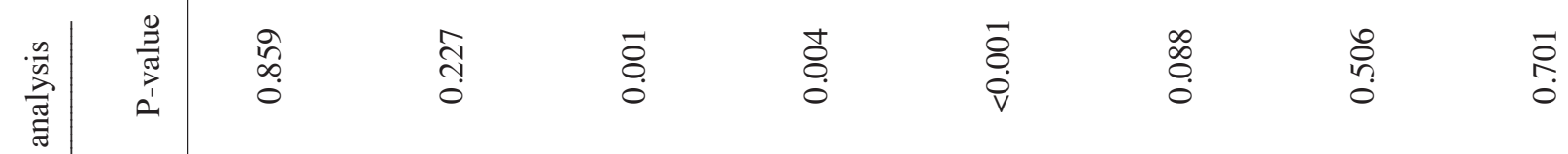

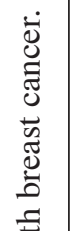

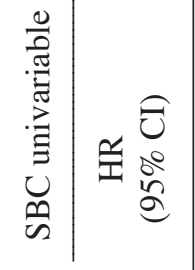

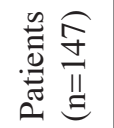

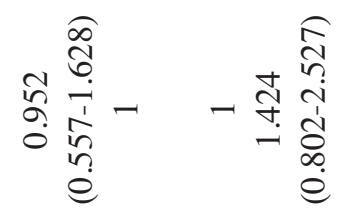

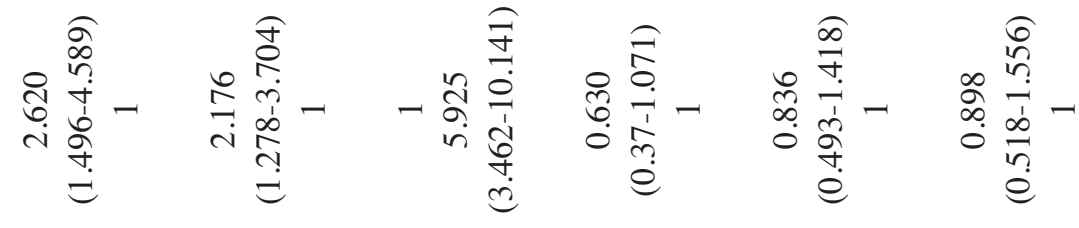

$$
\begin{aligned}
& \text { ช) }
\end{aligned}
$$

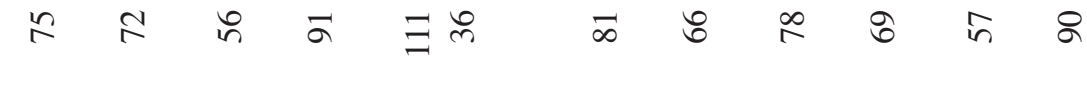

$$
\begin{aligned}
& \begin{array}{llll}
\stackrel{n}{n} & \stackrel{n}{n} & \frac{1}{0} & = \\
0 & 0 & 0
\end{array}
\end{aligned}
$$

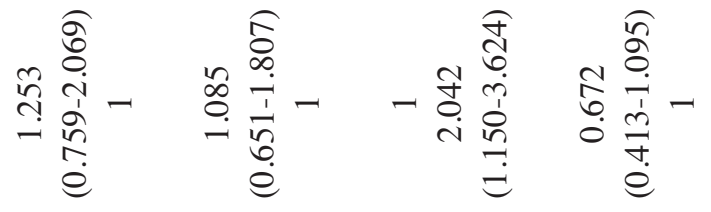

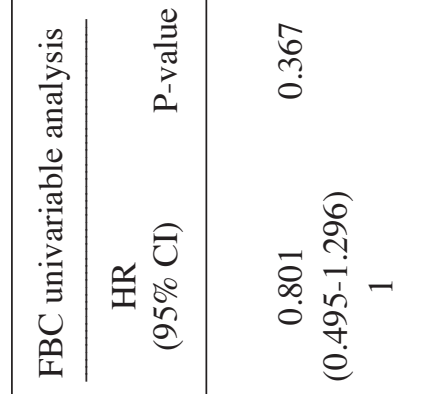

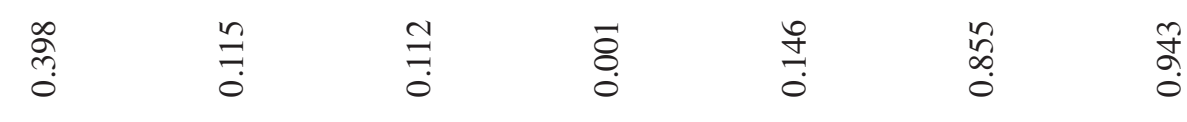

$$
\begin{aligned}
& \text { : }
\end{aligned}
$$




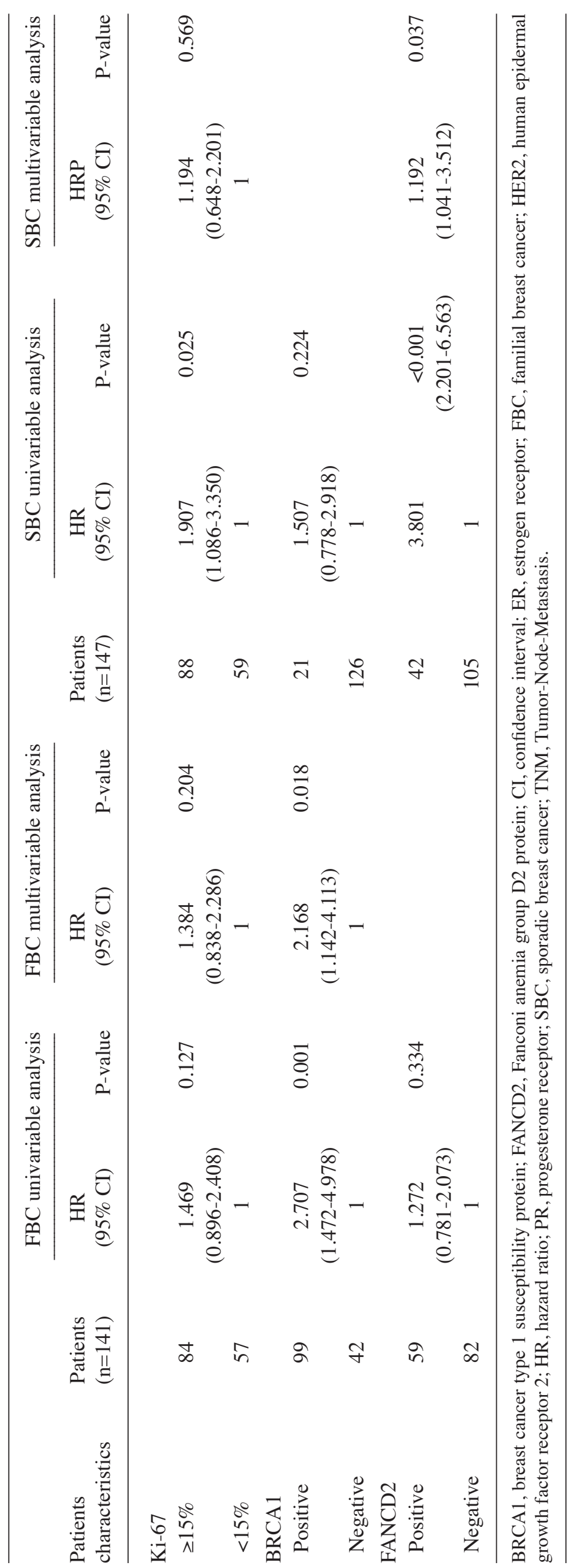




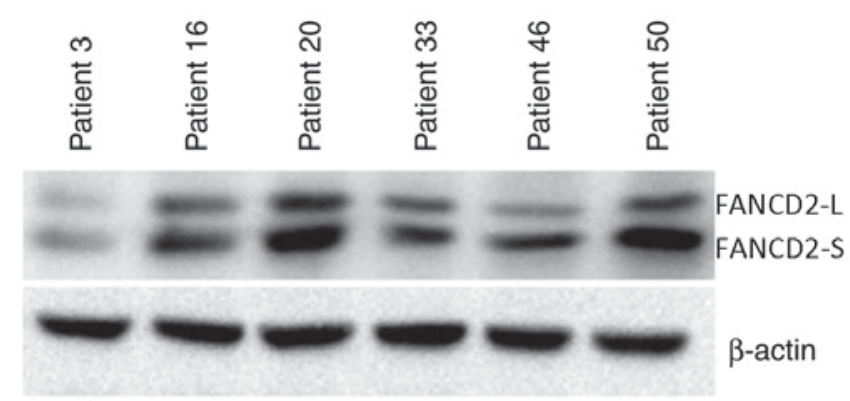

Figure 4. Western blot analysis of FANCD2 in patients with SBC. FANCD2 is represented by two adjacent bands. The upper stripe, L, is ubiquitinated FANCD2, and the lower stripe, S, is unubiquitinated FANCD2. Western blotting from the other 50 patients are shown in Fig. S1. BRCA1, breast cancer type 1 susceptibility protein; FANCD2, Fanconi anemia group D2 protein.

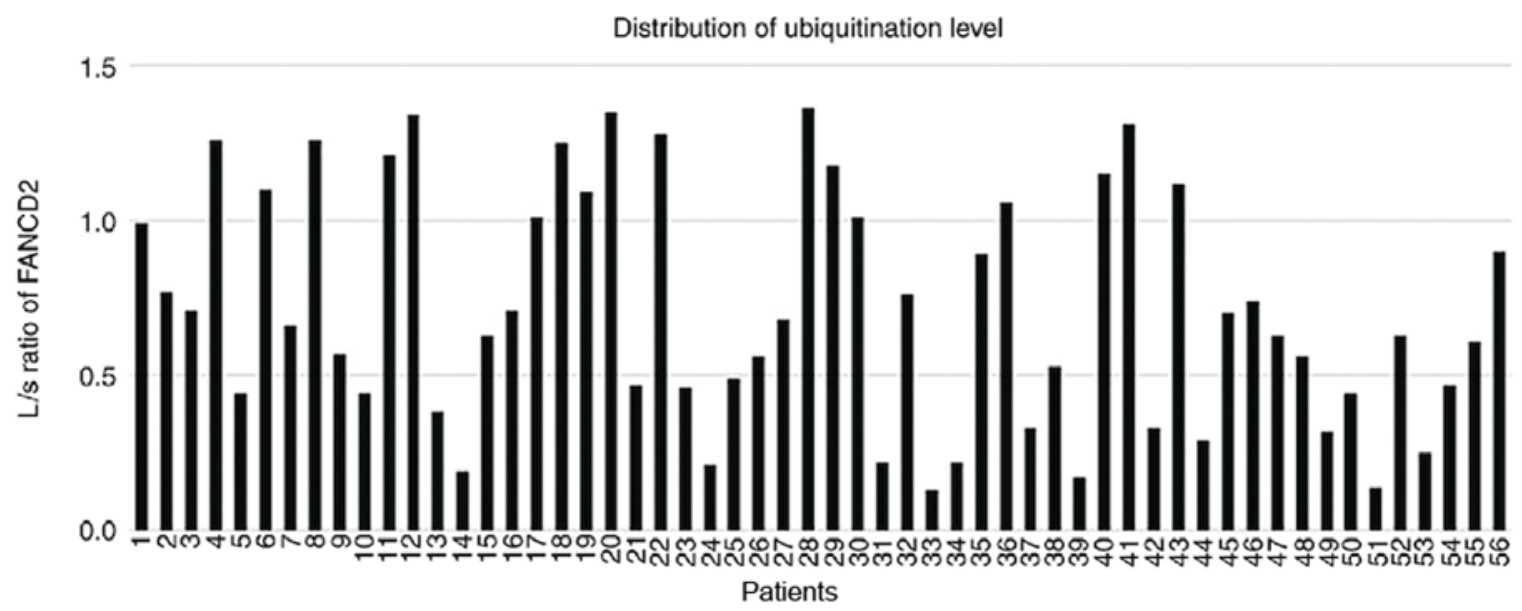

Figure 5. Distribution of ubiquitination levels of patients with SBC. The L/S ratio of 56 patients with SBC ranged from 0.13 to 1.36 , with a median ratio of 0.645. Cases were divided into FANCD2 $2^{\text {High }}$ and FANCD2 ${ }^{\text {Low }}$ groups according to the median L/S ratio of 0.645 (28 cases in each group). FANCD2, Fanconi anemia group D2 protein; SBC, sporadic breast cancer; L/S, ubiquitinated/unubiquitinated.

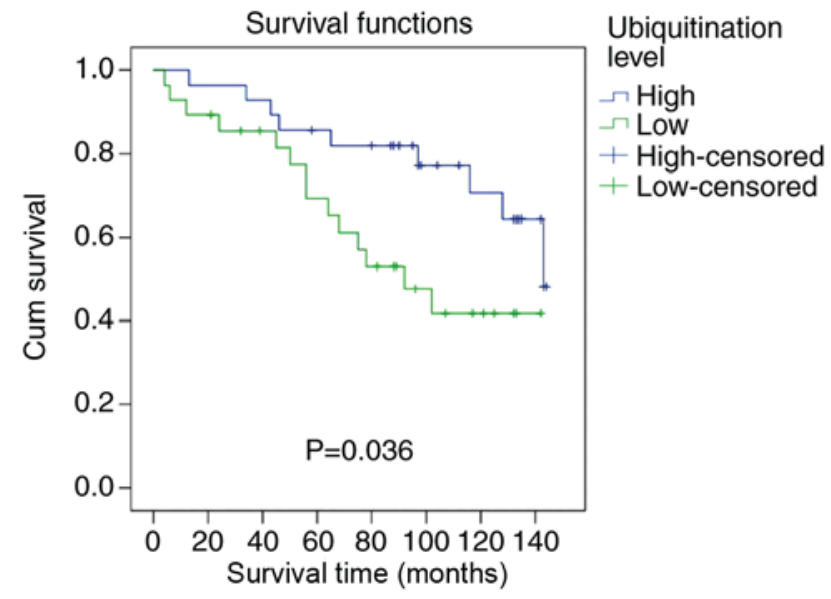

Figure 6. DFS of patients with SBC based on the ubiquitination level of FANCD2. DFS of patients divided into FANCD2 $2^{\text {High }}$ and FANCD2 $2^{\text {Low }}$ groups in the SBC group. Probabilities of DFS were estimated using the Kaplan-Meier method and compared using the log-rank statistic. DFS, disease-free survival; FANCD2, Fanconi anemia group D2 protein; SBC sporadic breast cancer.

from the present study demonstrated the positive association between FANCD2 and Ki-67 expression in the SBC group (40). Zhang et al (41) reported that BC tissues exhibit a significantly lower proportion of FANCD2-positive cells compared with healthy breast tissue; however, the present study did not demonstrate similar results, which may be due to the low number of benign cases included.

In the present study, high FANCD2 expression could independently predict a poor prognosis in the SBC group. These results were similar to those reported in previous studies $(19,42)$. We hypothesize that high FANCD2 expression may elevate the risk of early recurrence and distant metastasis, since it induces increased tolerability of the cancer cells to chemotherapy and radiotherapy. Radiotherapy and chemotherapy cause DNA damage that might be stabilized by upregulated DNA damage repair in tumor cells, which would result in a relatively poor prognosis $(39,40)$. Pejovic et al (43) reported that FANCD2-knockdown in mice stimulates ovarian cancer development; however, the manner in which FANCD2 affects the development of breast and ovarian cancer remains unclear.

Monoubiquitination of FANCD2 allows its translocation to the DNA repair complex through BRCA1 (44). FANCD2 monoubiquitination is therefore an important step that drives chromatin-associated complex assembly $(45,46)$ in response to DNA damage (47) during the S-phase of the normal cell cycle or during replicative stress $(48,49)$. The present study demonstrated that high FANCD2 expression was associated 
Table V. Univariable and multivariable analyses of disease-free survival in patients with sporadic breast cancer ( $\mathrm{n}=141)$.

\begin{tabular}{|c|c|c|c|c|c|}
\hline \multirow[b]{2}{*}{ Patients characteristics } & \multirow[b]{2}{*}{$\mathrm{n}$} & \multicolumn{2}{|c|}{ Univariable analysis } & \multicolumn{2}{|c|}{ Multivariable analysis } \\
\hline & & $\mathrm{HR}(95 \% \mathrm{CI})$ & P-value & HR $(95 \%$ CI $)$ & P-value \\
\hline \multicolumn{6}{|l|}{ Tumor size, $\mathrm{cm}$} \\
\hline$>2$ & 30 & $2.266(0.956-5.369)$ & 0.063 & $1.329(0.459-3.847)$ & 0.6 \\
\hline$\leq 2$ & 26 & 1 & & 1 & \\
\hline \multicolumn{6}{|l|}{ Lymphatic invasion } \\
\hline Positive & 27 & $2.545(1.071-6.050)$ & 0.034 & $2.485(0.896-6.895)$ & 0.08 \\
\hline Negative & 29 & 1 & & 1 & \\
\hline \multicolumn{6}{|l|}{ TNM stage } \\
\hline I-II & 39 & 1 & $<0.001$ & 1 & 0.003 \\
\hline III-IV & 17 & $6.389(2.687-15.190)$ & & $4.236(1.658-10.820)$ & \\
\hline \multicolumn{6}{|l|}{ ER status } \\
\hline Positive & 31 & $0.700(0.308-1.594)$ & 0.396 & & \\
\hline Negative & 25 & 1 & & & \\
\hline \multicolumn{6}{|l|}{ Ki-67 status } \\
\hline$\geq 15 \%$ & 41 & $1.946(0.708-5.348)$ & 0.197 & $1.705(0.520-5.584)$ & 0.378 \\
\hline$<15 \%$ & 15 & 1 & & 1 & \\
\hline \multicolumn{6}{|l|}{ FANCD2 } \\
\hline Positive & 18 & $3.133(1.370-7.169)$ & 0.007 & $3.755(1.465-9.625)$ & 0.006 \\
\hline Negative & 38 & 1 & & 1 & \\
\hline \multicolumn{6}{|l|}{ Ubiquitination level } \\
\hline$\geq 0.645$ & 28 & $0.403(0.167-0.968)$ & 0.042 & $0.335(0.128-0.875)$ & 0.026 \\
\hline$<0.645$ & 28 & 1 & & 1 & \\
\hline
\end{tabular}

FANCD2, Fanconi anemia group D2 protein; CI, confidence interval; ER, estrogen receptor; HR, hazard ratio; TNM, Tumor-Node-Metastasis.

with a poor prognosis. The L/S ratio was used to examine the prognostic value of FANCD2 monoubiquitination status. In patients with $\mathrm{SBC}$, a low $\mathrm{L} / \mathrm{S}$ ratio independently predicted a poor prognosis; however, this ratio had no prognostic value in patients with FBC.

The FA/BRCA pathway involves two of the most important BC susceptibility genes, which encode BRCA1 and FANCD1/BRCA2 (50). BRCA1 participates in the repair process with FANCD2. In the present study, a positive association was found between FANCD2 and BRCA1 expression in patients with FBC. Kais et al (51) reported that BRCA1-deficient cells upregulate FANCD2 expression, which is crucial for cell survival and the maintenance of genomic stability, whereas FANCD2 downregulation inhibits BRCA1-deficient cells survival.Lyakhovich and Surralles (37) revealed that FANCD2 gene expression is strongly associated with the repopulation ability of cancer cells, and that FANCD2 depletion in these cells decreases their recurrence ability. Li et al (52) suggested that increasing the specificity of the mitoxantrone cytotoxic agent may locally target the tumors and the BRCA1/2 network to induce the cellular sensitivity of tumors with homologous recombination deficiencies. Taniguchi et al reported that mutations of FA-related genes (FANCA, FANCC, FANCD2, FANCE, FANCF and FANCG) without BRCA1 mutations are rare among patients with SBC and their family members (53). In addition, the present study demonstrated that lower FANCD2 ubiquitination level and poor prognosis of patients with SBC may be due to the suppressed conversion of FANCD2-S into FANCD2-L, which may be associated with abnormal function of the E3 ubiquitination ligase complex. Wu et al (54) reported that the product of BRCA1 expression has E3 ubiquitin ligase activity and catalyzes the ubiquitination of various substrate proteins (e.g., FANCD2, NPM and RNAPII). BRAC1 therefore aids in the regulation of cell life processes and is closely associated with tumor occurrence and development.

The main limitation to the present study was that only the association between patient clinical characteristics and $\mathrm{BC}$ prognosis was analyzed. The specific mechanisms of the BRCA1 and FANCD2 genes with regard to prognosis, and the reasons behind the differences in their expression in FBC and SBC were not investigated. Additional experiments using breast cancer cells and animal model are required in future investigations.

In conclusion, the present study revealed that high BRCA1 expression was associated with a poor prognosis in patients with FBC. In addition, high FANCD2 expression and low FANCD2 ubiquitination were associated with a poor prognosis in patients with SBC. These results suggested that BRCA1 and FANCD2 expression and FANCD2 ubiquitination status may be considered as crucial markers that may assist in conducting pathogenesis research and risk assessment, forming an 
early diagnosis and developing gene therapy. Targeting the FA/BRCA pathway may represent a novel therapeutic option, which could improve the prognosis of patients with $\mathrm{BC}$.

\section{Acknowledgements}

Not applicable.

\section{Funding}

This study was partially supported by the Natural Science Foundation of Liaoning Province, P.R. China (grant no. 81773163) and the Liaoning Province Doctoral Research Startup Fund (grant no. 20170520404).

\section{Availability of data and materials}

The datasets used and/or analyzed during the present study are available from the corresponding author on reasonable request.

\section{Authors' contributions}

LF and FJ drafted the manuscript. LF assisted with immunohistochemistry and western blot analysis. FJ contributed to statistical analysis. All authors have read and approved the final manuscript.

\section{Ethics approval and consent to participate}

The present study was approved by the Ethics Committee of The First Affiliated Hospital of China Medical University, Shenyang, China (no. 2016-109-2). All patients enrolled in the present study signed informed consent.

\section{Patient consent for publication}

Not applicable.

\section{Competing interests}

The authors declare that they have no competing interests.

\section{References}

1. Wendt C, Lindblom A, Arver B, von Wachenfeldt A and Margolin S: Tumour spectrum in non-brca hereditary breast cancer families in sweden. Hered Cancer Clin Pract 13: 15, 2015.

2. Stratton MR and Rahman N: The emerging landscape of breast cancer susceptibility. Nat Genet 40: 17-22, 2008.

3. Rebbeck TR, Mitra N, Wan F, Sinilnikova OM, Healey S, McGuffog L, Mazoyer S, Chenevix-Trench G, Easton DF, Antoniou AC, et al: Association of type and location of BRCA1 and BRCA2 mutations with risk of breast and ovarian cancer. JAMA 313: 1347-1361, 2015.

4. Bhattacharjee S and Nandi S: DNA damage response and cancer therapeutics through the lens of the Fanconi Anemia DNA repair pathway. Cell Commun Signal 15: 41, 2017.

5. Dong H, Nebert DW, Bruford EA, Thompson DC, Joenje H and Vasiliou V: Update of the human and mouse Fanconi anemia genes. Hum Genomics 9: 32, 2015.

6. Garcia-Higuera I, Taniguchi T, Ganesan S, Meyn MS, Timmers C, Hejna J, Grompe M and D'Andrea AD: Interaction of the Fanconi anemia proteins and BRCA1 in a common pathway. Mol Cell 7: 249-262, 2001
7. Smogorzewska A, Matsuoka S, Vinciguerra P, McDonald ER III, Hurov KE, Luo J, Ballif BA, Gygi SP, Hofmann K, D'Andrea AD and Elledge SJ: Identification of the FANCI protein, a monoubiquitinated FANCD2 paralog required for DNA repair. Cell 129: 289-301, 2007.

8. Kee Y and D'Andrea AD: Molecular pathogenesis and clinical management of Fanconi anemia. J Clin Invest 122: 3799-3806, 2012.

9. Timmers C, Taniguchi T, Hejna J, Reifsteck C, Lucas L, Bruun D, Thayer M, Cox B, Olson S, D'Andrea AD, et al: Positional cloning of a novel Fanconi anemia gene, FANCD2. Mol Cell 7: 241-248, 2001.

10. Zhu J, Su F, Mukherjee S, Mori E, Hu B and Asaithamby A: FANCD2 influences replication fork processes and genome stability in response to clustered DSBs. Cell Cycle 14: 1809-1822, 2015.

11. Crossan GP and Patel KJ: The Fanconi anaemia pathway orchestrates incisions at sites of crosslinked DNA. J Pathol 226: 326-337, 2012.

12. Bunting SF and Nussenzweig A: Dangerous liaisons: Fanconi anemia and toxic nonhomologous end joining in DNA crosslink repair. Mol Cell 39: 164-166, 2010.

13. Schlacher K, Wu H and Jasin M: A distinct replication fork protection pathway connects Fanconi anemia tumor suppressors to RAD51-BRCA1/2. Cancer Cell 22: 106-116, 2012.

14. Ali AM, Pradhan A, Singh TR, Du C, Li J, Wahengbam K, Grassman E, Auerbach AD, Pang Q and Meetei AR: FAAP20: A novel ubiquitin-binding FA nuclear core-complex protein required for functional integrity of the FA-BRCA DNA repair pathway. Blood 119: 3285-3294, 2012.

15. Domchek SM, Tang J, StopferJ,Lilli DR, HamelN, Tischkowitz M, Monteiro AN, Messick TE, Powers J, Yonker A, et al: Biallelic deleterious BRCA1 mutations in a woman with early-onset ovarian cancer. Cancer Discov 3: 399-405, 2013.

16. Gradishar WJ, Anderson BO, Balassanian R, Blair SL, Burstein HJ, Cyr A, Elias AD, Farrar WB, Forero A, Giordano SH, et al: NCCN guidelines insights: Breast cancer, version 1.2017. J Natl Compr Canc Netw 15: 433-451, 2017.

17. Wen T, Wang Z, Li Y, Che X, Fan Y, Wang S, Qu J, Yang X, Hou K, Zhou W, et al: A four-factor immunoscore system that predicts clinical outcome for stage II/III gastric cancer. Cancer Immunol Res 5: 524-534, 2017.

18. Madjd Z, Karimi A, Molanae S and Asadi-Lari M: BRCA1 protein expression level and CD44(+)phenotype in breast cancer patients. Cell J 13: 155-162, 2011.

19. Rudland PS, Platt-Higgins AM, Davies LM, de Silva Rudland S, Wilson JB, Aladwani A, Winstanley JH, Barraclough DL, Barraclough R, West CR and Jones NJ: Significance of the Fanconi anemia FANCD2 protein in sporadic and metastatic human breast cancer. Am J Pathol 176: 2935-2947, 2010.

20. Ling C, Ishiai M, Ali AM, Medhurst AL, Neveling K, Kalb R, Yan Z, Xue Y, Oostra AB, Auerbach AD, et al: FAAP100 is essential for activation of the Fanconi anemia-associated DNA damage response pathway. EMBO J 26: 2104-2114, 2007.

21. Virts EL, Jankowska A, Mackay C, Glaas MF, Wiek C, Kelich SL, Lottmann N, Kennedy FM, Marchal C, Lehnert E, et al: AluY-mediated germline deletion, duplication and somatic stem cell reversion in UBE2T defines a new subtype of Fanconi anemia. Hum Mol Genet 24: 5093-5108, 2015.

22. Huang Z, Duan H and Li H: Identification of gene expression pattern related to breast cancer survival using integrated TCGA datasets and genomic tools. Biomed Res Int 2015: 878546, 2015.

23. Tang Z, Li C, Kang B, Gao G, Li C and Zhang Z: GEPIA: A web server for cancer and normal gene expression profiling and interactive analyses. Nucleic Acids Res 45: W98-W102, 2017.

24. Chavez-MacGregor M, Mittendorf EA, Clarke CA, Lichtensztajn DY, Hunt KK and Giordano SH: Incorporating tumor characteristics to the American Joint Committee on cancer breast cancer staging system. Oncologist 22: 1292-1300, 2017.

25. Collaborative Group on Hormonal Factors in Breast Cancer: Familial breast cancer: Collaborative reanalysis of individual data from 52 epidemiological studies including 58209 women with breast cancer and 101986 women without the disease. Lancet 358: 1389-1399, 2001.

26. Tazzite A, Jouhadi H, Saiss K, Benider A and Nadifi S: Relationship between family history of breast cancer and clinicopathological features in Moroccan patients. Ethiop J Health Sci 23: 150-157, 2013. 
27. Aleskandarany M, Caracappa D, Nolan CC, Macmillan RD, Ellis IO, Rakha EA and Green AR: DNA damage response markers are differentially expressed in BRCA-mutated breast cancers. Breast Cancer Res Treat 150: 81-90, 2015.

28. Troudi W, Uhrhammer N, Ben Romdhane K, Sibille C, Mahfoudh W, Chouchane L, Ben Ayed F, Bignon YJ and Ben Ammar Elgaaied A: Immunolocalization of BRCA1 protein in tumor breast tissue: Prescreening of BRCA1 mutation in Tunisian patients with hereditary breast cancer? Eur J Histochem 51: 219-226, 2007.

29. Sun X, Gong Y, Rao MS and Badve S: Loss of BRCA1 expression in sporadic male breast carcinoma. Breast Cancer Res Treat 71: $1-7,2002$.

30. Kenemans P, Verstraeten RA and Verheijen RH: Oncogenic pathways in hereditary and sporadic breast cancer. Maturitas 49 : 141-150, 2008

31. Russo A, Herd-Smith A, Gestri D, Bianchi S, Vezzosi V, Rosselli Del Turco M and Cardona G: Does family history influence survival in breast cancer cases? Int J Cancer 99: 427-430, 2002.

32. Tsuchiya A, Kanno M, Nomizu T, Hatakeyama Y, Kimijima I and Abe R: Clinical characteristics of breast cancer patients with family history. Fukushima J Med Sci 44: 35-41, 1998.

33. Esteller M, Silva JM, Dominguez G, Bonilla F, Matias-Guiu X, Lerma E, Bussaglia E, Prat J, Harkes IC, Repasky EA, et al Promoter hypermethylation and BRCA1 inactivation in sporadic breast and ovarian tumors. J Natl Cancer Inst 92: 564-569, 2000.

34. Walsh T, Casadei S, Coats KH, Swisher E, Stray SM, Higgins J, Roach KC, Mandell J, Lee MK, Ciernikova S, et al: Spectrum of mutations in BRCA1, BRCA2, CHEK2, and TP53 in families at high risk of breast cancer. JAMA 295: 1379-1388, 2006.

35. Scully R and Livingston DM: In search of the tumour-suppressor functions of BRCA1 and BRCA2. Nature 408: 429-432, 2000.

36. Sakaguchi C, Morishita T, Shinagawa $\mathrm{H}$ and Hishida T: Essential and distinct roles of the F-box and helicase domains of Fbh1 in DNA damage repair. BMC Mol Biol 9: 27, 2008

37. Lyakhovich A and Surralles J: FANCD2 depletion sensitizes cancer cells repopulation ability in vitro. Cancer Lett 256 186-195, 2007.

38. Wysham WZ, Mhawech-Fauceglia P, Li H, Hays L, Syriac S, Skrepnik T, Wright J, Pande N, Hoatlin M and Pejovic T: BRCAness profile of sporadic ovarian cancer predicts disease recurrence. PLoS One 7: e30042, 2012.

39. van der Groep P, Hoelzel M, Buerger H, Joenje H, de Winter JP and van Diest PJ: Loss of expression of FANCD2 protein in sporadic and hereditary breast cancer. Breast Cancer Res Treat 107: 41-47, 2008.

40. Hölzel M, van Diest PJ, Bier P, Wallisch M, Hoatlin ME, Joenje H and de Winter JP: FANCD2 protein is expressed in proliferating cells of human tissues that are cancer prone in Fanconi anaemia. J Pathol 201: 198-203, 2003.

41. Zhang B, Chen R, Lu J, Shi Q, Zhang X and Chen J: Expression of FANCD2 in sporadic breast cancer and clinicopathological analysis. J Huazhong Univ Sci Technolog Med Sci 30: 322-325, 2010.
42. Fagerholm R, Sprott K, Heikkinen T, Bartkova J, Heikkilä P, Aittomäki K, Bartek J, Weaver D, Blomqvist C and Nevanlinna H: Overabundant FANCD2, alone and combined with NQO1, is a sensitive marker of adverse prognosis in breast cancer. Ann Oncol 24: 2780-2785, 2013

43. Pejovic T, Yates JE, Liu HY, Hays LE, Akkari Y, Torimaru Y, Keeble W, Rathbun RK, Rodgers WH, Bale AE, et al: Cytogenetic instability in ovarian epithelial cells from women at risk of ovarian cancer. Cancer Res 66: 9017-9025, 2006.

44. Vandenberg CJ, Gergely F, Ong CY, Pace P, Mallery DL, Hiom K and Patel KJ: BRCA1-independent ubiquitination of FANCD2. Mol Cell 12: 247-254, 2003.

45. Montes de Oca R, Andreassen PR, Margossian SP, Gregory RC, Taniguchi T, Wang X, Houghtaling S, Grompe M and D'Andrea AD: Regulated interaction of the Fanconi anemia protein, FANCD2, with chromatin. Blood 105: 1003-1009, 2005.

46. Park WH, Margossian S, Horwitz AA, Simons AM, D'Andrea AD and Parvin JD: Direct DNA binding activity of the Fanconi anemia D2 protein. J Biol Chem 280: 23593-23598, 2005.

47. Hussain S, Wilson JB, Medhurst AL, Hejna J, Witt E, Ananth S, Davies A, Masson JY, Moses R, West SC, et al: Direct interaction of FANCD2 with BRCA2 in DNA damage response pathways. Hum Mol Genet 13: 1241-1248, 2004.

48. Taniguchi T, Garcia-Higuera I, Andreassen PR, Gregory RC, Grompe $M$ and D'Andrea AD: S-phase-specific interaction of the Fanconi anemia protein, FANCD2, with BRCA1 and RAD51. Blood 100: 2414-2420, 2002.

49. Rothfuss A and Grompe M: Repair kinetics of genomic interstrand DNA cross-links: Evidence for DNA double-strand break-dependent activation of the Fanconi anemia/BRCA pathway. Mol Cell Biol 24: 123-134, 2004.

50. Wang W: Emergence of a DNA-damage response network consisting of Fanconi anaemia and BRCA proteins. Nat Rev Genet 8: 735-748, 2007.

51. Kais Z, Rondinelli B, Holmes A, O'Leary C, Kozono D, D'Andrea $\mathrm{AD}$ and Ceccaldi R: FANCD2 maintains fork stability in BRCA1/2-deficient tumors and promotes alternative end-joining DNA repair. Cell Rep 15: 2488-2499, 2016.

52. Li Y, Zhao L, Sun H, Yu J, Li N, Liang J, Wang Y, He M, Bai X, Yu Z, et al: Gene silencing of FANCF potentiates the sensitivity to mitoxantrone through activation of JNK and p38 signal pathways in breast cancer cells. PLoS One 7: e44254, 2012.

53. Barroso E, Milne RL, Fernández LP, Zamora P, Arias JI, Benítez J and Ribas G: FANCD2 associated with sporadic breast cancer risk. Carcinogenesis 27: 1930-1937, 2006.

54. Wu W, Koike A, Takeshita T and Ohta T: The ubiquitin E3 ligase activity of BRCA1 and its biological functions. Cell Div 3: 1, 2008.

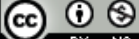

This work is licensed under a Creative Commons Attribution 4.0 International (CC BY-NC 4.0) License 